\title{
Presença do antropólogo Carlo Castaldi no Brasil - 1953 a 1958
}

Carlos Caroso

Carlo Castaldi é um nome pouco presente e lembrado nas ciências sociais no Brasil; quando isto ocorre as referências são sempre feitas a seu trabalho denominado "A aparição do demônio no Catulé", que se tornou um clássico nos estudos de religiosidade popular. Não sendo este seu único trabalho publicado durante sua estadia no Brasil de 1953 a 1958, veio a ser o mais conhecido e importante. Considero que isto se deva não apenas a este ser um precursor dos estudos antropológicos sistemáticos sobre religiosidade popular realizado por um antropólogo com formação acadêmica específica, mas também por se tratar de um movimento messiânico da Igreja Adventista da Promessa, que culminou na morte de quatro crianças acusadas de estarem possuídas pelo demônio, e, por fim, pela parceria com estudiosos brasileiros que dariam significativas contribuições em suas áreas de atuação.

O primeiro contato que tivemos se deu em 1996, quando recebi uma mensagem através da internet, na qual ele dizia ter trabalhado na Bahia nos anos de 1950 e me indagava se eu poderia responder algumas perguntas sobre pessoas que conhecera. Respondi afirmativamente, tratando-o como professor Castaldi, já que o associei a alguma leitura feita ao longo de minha carreira de antropólogo e pesquisador, tendo ele respondido que infelizmente não se tornara professor, pois a vida o conduzira por outros caminhos e nunca terminara seu doutorado na Universidade de Columbia. Enviou-me um texto que há algum tempo disponibilizara na internet, em 
que relatava seu trabalho de campo na Ilha de Itaparica entre 1953 e 1954, e solicitava informaçôes sobre alguns dos seus antigos interlocutores de pesquisa; finalizando ele declarava que se sentia como "um naufragado que lança uma garrafa ao mar sem saber o que virá".

Mantivemos contato assíduo por correio eletrônico até que no ano seguinte nos encontramos em Roma. Nosso primeiro encontro deu-se no hotel em que eu me hospedava, tendo ele, após nossa conversa sobre pessoas e fatos na Bahia, acompanhado-me à estação ferroviária Termini, onde embarquei para Perúgia para trabalhar num projeto de pesquisa com Tullio Seppilli, antropólogo italiano que residiu em São Paulo na década de 1940, onde sua família refugiou-se da perseguição fascista a judeus e comunistas; ele, em ambas as condições, sequer podia freqüentar escola na Itália. Seppilli conhecia Castaldi, com quem trabalhara em projetos de desenvolvimento. Nesta oportunidade restabeleceram o contato perdido há muitos anos. Ao retornar a Roma uma semana mais tarde, tivemos nosso segundo encontro, ocasião em que Castaldi, para minha total surpresa, ofereceu-me a versão original de sua tese, datilografada em língua inglesa, solicitando-me que fizesse uso acadêmico de seu material "se este tivesse algum valor".

Retornando à Bahia li o texto cuidadosamente, achando-o de boa qualidade e sobretudo rico em informaçôes sobre um momento importante no cotidiano da Ilha de Itaparica não registrado por qualquer outro pesquisador. O texto foi escrito sob influência dos estudos de comunidade, uma característica comum aos participantes do programa Columbia-UFBA, com forte influência funcionalista, de maneira, às vezes, preciosamente descritiva, carente de melhores contextualizaçôes e sobretudo de arcabouço teórico e interpretaçôes mais sólidas. Por outro lado, seus estudos guardam uma característica diferenciada em relação à tendência presente na época, da etnografia focalizada e orientada para a compreensão de problemas por meio de cuidadosas descrições e interpretações contextualizadas.

O próximo passo foi solicitar-lhe que escrevesse uma apresentação de seu material na qual relatasse sua experiência pessoal no campo, com vistas a melhor detalhar o contexto e as circunstâncias nas quais foram produzidos os dados do seu estudo. Em outubro de 1999, ele respondeu a meu pedido enviando-me um texto, escrito em bem cuidado português e autoreflexivo, cujo título era "Recordando Itaparica (1953/1954)", no qual falava sobre seu trabalho de campo na Bahia, os resultados obtidos, a curta permanência no Rio de Janeiro, o período em que residiu e trabalhou em São Paulo, as razōes que o levaram a afastar-se da antropologia acadêmica e 
sua visão crítica mais recente sobre as decisões que tomou que o impediram de terminar o doutorado.

O demônio em Catulé e o trabalho em São Paulo

Ao finalizar seu trabalho de campo na Bahia e enviar uma cópia para Charles Wagley na Universidade de Columbia, Castaldi atendeu ao convite para realizar um estudo com "colegas brasileiros, Carolina Martuscelli e Eunice Todescan Ribeiro [Eunice Ribeiro Durhan] de São Paulo e Paul Galery da Universidade de Minas Gerais, sobre um episódio de fanatismo religioso, acontecido em abril de 1955 na fazenda de São João da Mata, município de Malacacheta (Minas Gerais), onde um grupo de camponeses, membros da Igreja Adventista da Promessa, tinha assassinado quatro crianças acusadas de estarem possuídas pelo demônio" (Castaldi, 1999).

Este convite, assim como outro que recebeu ao fim de sua estadia no Brasil, alterou seu destino, visto que em vez de retornar para terminar e defender sua tese de doutorado, ele assumiu a responsabilidade de realizar novos estudos. A este fato ele se refere apenas discretamente em nota de pé de página no escrito sobre Itaparica, dizendo: "Para terminar a tese teria tido que, em vez de iniciar novos trabalhos, voltar à Universidade de Columbia, discutir o material recolhido com o meu relator, Prof. Charles (Chuck) Wagley e então voltar para Itaparica para remediar as lacunas do primeiro esboço."

Castaldi relata que os estudos realizados em Minas Gerais lhe exigiram muito tempo na coleta das informaçôes e na redação dos textos finais. Os artigos resultantes do estudo foram publicados na revista Anhembi em 1955. Em 1957 foram republicados, desta vez como capítulos num livro organizado por Maria Isaura Pereira de Queiroz, cujo título é Estudos de sociologia e história, com apresentação de Paulo Duarte, pela mesma Editora Anhembi de São Paulo. Este livro contém dois "Estudos de sociologia" com uma única introdução de Maria Isaura Pereira de Queiroz. Um é "A aparição do demônio em Catulé", em que quatro partes são de autoria de Castaldi: "Introdução", "Os fatos", "O grupo e seus problemas sócio-econômicos" e "Conclusão", e duas partes são de Eunice Todeschan Ribeiro: "A difusão do Adventismo da Promessa no Catulé", e de Carolina Martuscelli: "Estudo psicológico do grupo". O outro estudo, de autoria de Maria Isaura Pereira de Queiroz, são os artigos "Tambaú, cidade dos milagres" e "Um estudo de história: o mandonismo local na vida política brasileira”. 
$\mathrm{Na}$ apresentação geral escrita para o livro, Paulo Duarte comenta que "Em agosto do mesmo ano [1955] publicou na mesma revista [Anhembi] um primeiro trabalho de Carlo Castaldi, sob cuja direção se fez a pesquisa, e que era organizada sob o patrocínio do Instituto Nacional de Estudos Pedagógicos do Rio de Janeiro, do Departamento de Sociologia da Faculdade de Filosofia da Universidade de São Paulo e da Anhembi". Este "preâmbulo" foi incluído como uma parte introdutória ao trabalho "A aparição do demônio em Catulé".

Os fatores que vieram a fazer com que um estudo de um antropólogo que não completou seu doutorado (tornou-se consultor em projetos de desenvolvimento em países do Oriente Médio, engajou-se ativamente na promoção de relaçôes políticas e comerciais entre empresas petrolíferas italianas e produtores de petróleo de países árabes e desapareceu para a antropologia por quase meio século) se tornasse um marco nos estudos de religiosidade popular no Brasil são, aparentemente, de pelo menos três ordens.

Primeiro, a emergente antropologia social no Brasil teve, nos participantes do Projeto Unesco, importantes acadêmicos de diversos países (Brasil, França e Estados Unidos), promovendo intenso intercâmbio acadêmico e científico. Este fato veio a ter significativas repercussōes na formação de um novo campo da antropologia no Brasil sob a égide do funcionalismo norte-americano e dos estudos de comunidade, num momento em que a influência da antropologia francesa, particularmente em São Paulo, era ainda muito intensa, devido à importância da presença de Claude LéviStrauss e Roger Bastide como professores na USP nas décadas anteriores. Apesar de não ser novidade, pois essa mesma proposta de abordagem já se encontrava em discussão desde os estudos de Donald Pierson. Contudo, desta vez o envolvimento e a formação de cientistas sociais brasileiros por intermédio do Projeto Unesco deu-se em maior dimensão de número de participantes e estudos realizados.

Segundo, Castaldi foi um dos poucos pesquisadores deste grupo de norte-americanos, sendo ele italiano de origem mas estudante nos Estados Unidos, que desenvolveu trabalho em colaboração com estudiosos brasileiros e atendeu a uma demanda imediata de estudar um fenômeno que ocorrera naquele momento. Outros participantes do mesmo grupo limitaram-se a realizar seus estudos e retornar a suas instituiçôes de origem, seus trabalhos permanecendo quase desconhecidos no Brasil, a exemplo de Marvin Harris e William Hutchinson, que nunca tiveram seus estudos traduzidos e disponibilizados para acadêmicos brasileiros. 
Terceiro, na equipe liderada por Castaldi estavam duas jovens pesquisadoras brasileiras que contribuíram com a elaboração de textos específicos. Eunice Todescan Ribeiro estudou como o Adventismo da Promessa preenchia uma lacuna nas demandas religiosas e ritualísticas da população local, que se sentia descuidada pela Igreja Católica devido à pouca freqüência de padres em cerimônias católicas no local. Carolina Matuscelli, com formação em psicologia, realizou um estudo de grande importância, em que traçou o perfil psicológico daquela população ao compreender as motivações das pessoas para o desencadeamento do conjunto de ações que se seguiram, aplicando métodos e protocolos de avaliação psicológica bastante refinados para a época.

Por outro lado, pode-se notar em seus escritos que Castaldi não dialogava assiduamente com as tradiçôes teóricas da antropologia que orientavam seus trabalhos. Seu estudo em Itaparica não tem qualquer referência de autores da época. No estudo "A aparição do demônio no Catulé" são feitas raras referências bibliográficas, porém, é importante notar que ele foi leitor de autores brasileiros como Antonio Candido, cuja tese de doutorado, denominada "Parceiros de Rio Bonito", que só posteriormente veio a ser publicada, é repetidamente citada ao longo de seu texto, apossando-se, particularmente, da noção do "caipira" como a utiliza Candido. Contudo, ele não faz qualquer referência aos importantes estudos das décadas de $1930 \mathrm{e}$ 1950 e aos próprios participantes do projeto Unesco que o precederam, tanto na Bahia, onde teve início, como em São Paulo.

Sua etnografia sobre a aparição do demônio em Catulé é preciosamente descritiva e factual, buscando explicaçôes lógicas para as ocorrências que observa, porém ele, novamente, não dialoga teoricamente com as referências da época, nem com aquelas já clássicas nos estudos de religiōes, religiosidade e práticas de exorcismo em contextos religiosos comparados. Demonstra significativo cuidado na caracterização dos personagens, tanto do ponto de vista de suas trajetórias migratórias, por exemplo, como do ponto de vista de suas características físicas e perfis psicológicos, concluindo por buscar nestes a explicação para o ocorrido. Entre as explicações surge claramente a idéia de conflito presente nos processos migratórios, assim como as dificuldades de adaptação ao ambiente social em decorrência da conversão religiosa. Bastante em sintonia com o pensamento vigente da época, seu texto conclui que a crença religiosa criou condiçôes, porém as características psicológicas dos indivíduos são outro importante ingrediente na explicação para os fatos ocorridos. 
A importância que ganhou o estudo de Carlo Castaldi e seus colaboradores, e sua grande repercussão, foi avaliada em 1995, quando Renato da Silva Queiroz fez sua revisão crítica, publicada sob título "O caminho do Paraíso: o surto messiânico-milenarista do Catulé”, no volume 6 da coleção Religião e Sociedade Brasileira, publicado pela FFLCH/USP-CER.

Ao finalizar seu trabalho sobre as ocorrências no Catulé, logo em seguida, Castaldi participou de uma pesquisa sobre o tema "Mobilidade e trabalho na cidade de São Paulo", financiada pela Unesco e pelo Ministério da Educação do Brasil. Este estudo foi dirigido por Bertram Hutchinson, participando também Carolina Martuscelli, Juarez R. Brandão Lopes, de quem ele omite o prenome em seu texto. Os resultados foram publicados pelo Inep em 1960, depois que ele já havia deixado o Brasil.

Em julho de 1955, no momento em que realizava a pesquisa sobre os crimes no Catulé, Castaldi participou da II Reunião Brasileira de Antropologia, que foi realizada em Salvador quando da fundação da Associação Brasileira de Antropologia-ABA. Na ocasião ele apresentou um trabalho com o título "Consideraçóes sobre o processo de ascensão social do imigrante italiano em São Paulo", que foi publicado nos Anais da Reunião em edição da Universidade Federal da Bahia em 1957, trabalho este citado por Octavio Ianni (1963) em seu livro sobre industrialização e desenvolvimento social. Naquele momento essas reuniōes refletiam a dimensão da antropologia no Brasil, sendo possível ver todos os participantes, incluindo o jovem antropólogo Carlo Castaldi, na fotografia do evento, ocorrido no auditório principal do Instituto Geográfico e Histórico da Bahia-IGHBA.

Nascido em 30 de outubro de 1924, Carlo Castaldi morreu em 23 de agosto de 2002 vítima de doença neoplásica. Não deixou descendente, e logo após sua morte, sua única irmã, que veio a falecer dois meses mais tarde, incinerou todos seus documentos, que ele tinha intenção de trazer para a Bahia, onde deixaria sob guarda da UFBA.

Trabalhos, publicações e citações de Carlo Castaldi

Castaldi, Carlo. (1955), "Um exemplo de catolicismo de folk na Bahia”. Revista da Escola Livre de Sociologia e Política, São Paulo, 3 (XVII): 231-253.

. (1957), "Considerações sabre o processo de ascensão social do imigrante ita-

liano em São Paulo". Anais da II Reunião Brasileira de Antropologia, Edição da Universidade da Bahia, pp. 311-314. . (1999), Recordando Itaparica. Roma, manuscrito. 
. Songs and dances from Bahia. Ethnic Folkways. Long play, s/d.

et al. (1957), "A aparição de demônio em Catulé". In: Queiroz, Maria Isaura

Pereira de et al. (1957). Estudos de sociologia e história. São Paulo, Inep - Anhembi, pp. 17-130.

Hutchinson, Bertram A. (diretor da pesquisa). (1960), "Mobilidade e trabalho: um estudo na cidade de São Paulo". Rio de Janeiro, Centro Brasileiro de Pesquisas Educacionais -Inep.

IANNI, Octavio. (1963), Industrialização e desenvolvimento social no Brasil. Rio de Janeiro, Civilização Brasileira.

Martuscelli, C. (1957), "Estudo psicológico do grupo". In: Queiroz, Maria Isaura Pereira de et al. Estudos de sociologia e história. São Paulo, Anhembi - Inep.

Ribeiro, Eunice Todescan. (1957), "A difusão do Adventismo da Promessa no Catulé". In: Queiroz, Maria Isaura Pereira de et al. Estudos de sociologia e história. São Paulo, Anhembi - Inep.

Carlos Caroso é professor associado no Departamento de Antropologia e Etnologia da FFCH/UFBA e bolsista de produtividade em Pesquisa $1 \mathrm{D}$ do CNPq. E-mail: caroso@ufba. br. 